\title{
Behavioural estimation of blue whale movements in the Northeast Pacific from state-space model analysis of satellite tracks
}

\author{
Helen Bailey ${ }^{1, *, * *}$, Bruce R. Mate ${ }^{2, * *}$, Daniel M. Palacios ${ }^{1,3}$, Ladd Irvine $^{2}$, \\ Steven J. Bograd ${ }^{1}$, Daniel P. Costa ${ }^{4}$

\begin{abstract}
${ }^{1}$ NOAA/NMFS/SWFSC/Environmental Research Division, 1352 Lighthouse Avenue, Pacific Grove, California 93950, USA
${ }^{2}$ Marine Mammal Institute, Department of Fisheries and Wildlife, and Coastal Oregon Marine Experiment Station, Oregon State University, Hatfield Marine Science Center, 2030 SE Marine Science Drive, Newport, Oregon 97365, USA

${ }^{3}$ Joint Institute for Marine and Atmospheric Research, University of Hawaii at Manoa, 1000 Pope Road,
\end{abstract} \\ Marine Science Building 312, Honolulu, Hawaii 96822, USA \\ ${ }^{4}$ Ecology and Evolutionary Biology, Long Marine Laboratory, University of California, Santa Cruz, 100 Shaffer Road, \\ Santa Cruz, California 95060, USA
}

\begin{abstract}
Baleen whale migrations typically consist of annual movements between productive, high-latitude feeding grounds and unproductive, low-latitude breeding grounds. However, the actual migratory path and whales' behaviour in these locations are poorly known. The objectives of this study were to apply a switching state-space model to the satellite tracks of blue whales Balaenoptera musculus in the Northeast Pacific to improve location estimation and gain insight into the migratory (transiting) and foraging (area-restricted search, ARS) behaviours of this population. During the period 1993 to 2007, Argos satellite tags were attached to 159 whales, mainly off the coast of California during late summer, of which 92 tracks were $>7 \mathrm{~d}$ in duration. There was generally a southward movement during the winter to Baja California and to an area west of the Costa Rica Dome, in the eastern tropical Pacific (ETP). Travel speeds during transit were significantly faster than during ARS movements (mean $=3.70$ and $1.05 \mathrm{~km} \mathrm{~h}^{-1}$, respectively). On average, $29 \%$ of the track time was spent in ARS, and the mean time within an ARS patch was $21 \mathrm{~d}$. The occurrence of ARS behaviour throughout the migration cycle suggests that these animals may forage year-round, but could also indicate limited movements during the reproductive season. The extent of their northward migration from Baja California to Washington varied significantly interannually, likely in response to environmental changes affecting their prey. The long track durations obtained from electronic tagging have provided essential new information about the critical habitats of Northeast Pacific blue whales.
\end{abstract}

KEY WORDS: Balaenoptera musculus - Satellite telemetry $\cdot$ Area-restricted search - Migration · First-passage time $\cdot$ Foraging $\cdot$ Baja California $\cdot$ Eastern tropical Pacific

\section{INTRODUCTION}

In the pelagic marine environment, prey resources tend to be patchily distributed as a result of physical and biological processes (Ressler et al. 2005). Thus, it is expected that predators will reduce their travel speed and increase their turning angle when they have encountered prey so that they remain within the patch where the probability of capturing prey is high. This is referred to as area-restricted search (ARS) behaviour (Kareiva \& Odell 1987). Once the rate of prey intake decreases to the mean level within the environment 
(Charnov 1976), it is expected that the predator will move in a relatively straight path in search of the next prey patch (Zollner \& Lima 1999). Animal movement patterns can be distinguished using mathematical models such as a random walk, Lévy flight, fractal analysis, and first-passage time (Schick et al. 2008). However, errors in the observation process may erode the biological patterns and limit our ability to detect ARS behaviour (Bradshaw et al. 2007, Robinson et al. 2007). The application of state-space models, which can be used to couple a statistical model of the observation process (tracking locations and their associated errors) with a model of the movement dynamics (such as a random walk model), enables improved estimates of locations and their precision (Anderson-Sprecher \& Ledolter 1991, Jonsen et al. 2003, Patterson et al. 2008). The Bayesian switching state-space model (SSSM) developed by Jonsen et al. (2007) has been demonstrated to distinguish between 'transiting' (i.e. commuting between foraging patches or migration between breeding and feeding grounds) and 'foraging' (i.e. ARS) behavioural modes.

Annual migrations are a common feature of the life history of baleen whales and include the longest movement (approximately $8300 \mathrm{~km}$ ) for any mammal ever recorded (Rasmussen et al. 2007). In general, baleen whale migrations are movements between productive, high-latitude feeding grounds and unproductive, lowlatitude breeding grounds (Brodie 1975, Corkeron \& Connor 1999). However, there is evidence that blue whales also feed in low-latitude areas (Reilly \& Thayer 1990, Branch et al. 2007); thus, foraging and reproduction may not be temporally or spatially segregated. Blue whales are stenophagic predators, feeding almost exclusively on euphausiids (Sears \& Perrin 2009). They are common in areas of upwelling and frontal meandering, where phytoplankton, and consequently euphausiid, concentrations are high (Fiedler et al. 1998, Etnoyer et al. 2006, Branch et al. 2007). Early satellite tracking of blue whales in the Northeast Pacific revealed that the locations exhibited a clumped pattern in an area where they were known to feed (Mate et al. 1999), suggesting they use ARS behaviour. However, there has previously been insufficient information on individual movements to test this.

The objectives of the present study were to apply an SSSM (Jonsen et al. 2007) to the satellite tracks of blue whales in the Northeast Pacific to improve location estimation and to gain insight into the ecology of the species based on seasonal and interannual differences between transiting and ARS behaviours. The evolution of tagging during the $14 \mathrm{yr}$ period 1993 to 2007 also allowed us to assess the effect of variable track durations and satellite transmission schedules on the performance of the SSSM.

\section{MATERIALS AND METHODS}

Data collection. Satellite-monitored radio transmitter tags were attached to 159 blue whales during August to October in 1993 to 2007 (except 1996, 1997, and 2003). The main deployment location was off southern California, at the west end of the Santa Barbara Channel, but tags were also deployed in the Gulf of the Farallones, near Cape Mendocino, and in the Gulf of California, Mexico (Fig. 1a). The tags were attached 1 to $4 \mathrm{~m}$ forward of the dorsal fin from a small ( 5 to $7 \mathrm{~m}$ ) rigid-hulled inflatable boat. Prior to 1996, tags were applied with a $68 \mathrm{~kg}$ Barnett compound crossbow. For that period, the tags were Telonics transmitters (ST-6 or ST-10) housed in stainless-steel cylinders that were attached to the whale's back with 2 subdermal anchors to hold them in the blubber layer (Mate et al. 1999). Later, Telonics ST-15 transmitters were used that could be housed in an implantable stainless-steel cylinder partly covered with a long-term dispersant antibiotic coating (Mate et al. 2007). From 2002, tags were attached using a modified version of the Air Rocket Transmitter System (ARTS) air-powered applicator system (Heide-Jørgensen et al. 2001). Further details about tag design and deployment can be found in Mate et al. (2007). The satellite tracks of 10 of the whales tagged in 1994 and 1995 have been published in Mate et al. (1999), 4 of the whales tagged in 1998 in Etnoyer et al. (2004), and 2 from 2001 and 2002 in Etnoyer et al. (2006). This is the first publication to consider all of the tags from 1993 to 2007, representing the largest cetacean tagging data set to date.

SSSM. The SSSM developed by Jonsen et al. (2007) was applied to all of the raw Argos-acquired surface locations of each blue whale track. This model allows location estimates to be inferred from observed data (satellite locations) by accounting for errors (measurement equation) and from dynamics of the movement process (transition equation) (Patterson et al. 2008). The transition equation was based on a first-difference correlated random walk model and included a process model for each of 2 behavioural modes, which were defined based on the parameters mean turning angle $(\theta)$ and autocorrelation in speed and direction $\left(\gamma_{i}\right.$ Jonsen et al. 2005). The transition equation is specified as (Jonsen et al. 2005, 2007):

$$
\mathbf{d}_{\mathrm{t}} \sim N_{2}\left[\gamma_{b} \mathbf{T}\left(\theta_{b}\right) \mathbf{d}_{\mathrm{t}-1}, \Sigma\right]
$$

where $d_{t-1}$ is the difference between the unobserved coordinate states $\mathrm{x}_{\mathrm{t}-1}$ and $\mathrm{x}_{\mathrm{t}-2}$ (i.e. locations in latitude and longitude). $N_{2}$ is a bivariate Gaussian distribution with covariance matrix $\boldsymbol{\Sigma}$ and $\mathbf{T}$ is a transition matrix that describes the rotational component of the correlated random walk:

$\boldsymbol{\Sigma}=\left[\begin{array}{cc}\sigma_{\text {lon }}^{2} & \rho \sigma_{\text {lon }} \sigma_{\text {lat }} \\ \rho \sigma_{\text {lon }} \sigma_{\text {lat }} & \sigma_{\text {lat }}^{2}\end{array}\right], \quad 0 \leq \gamma_{b}<1, \quad \mathbf{T}\left(\theta_{b}\right)=\left[\begin{array}{cc}\cos \left(\theta_{b}\right) & -\sin \left(\theta_{b}\right) \\ \sin \left(\theta_{b}\right) & \cos \left(\theta_{b}\right)\end{array}\right]$ 

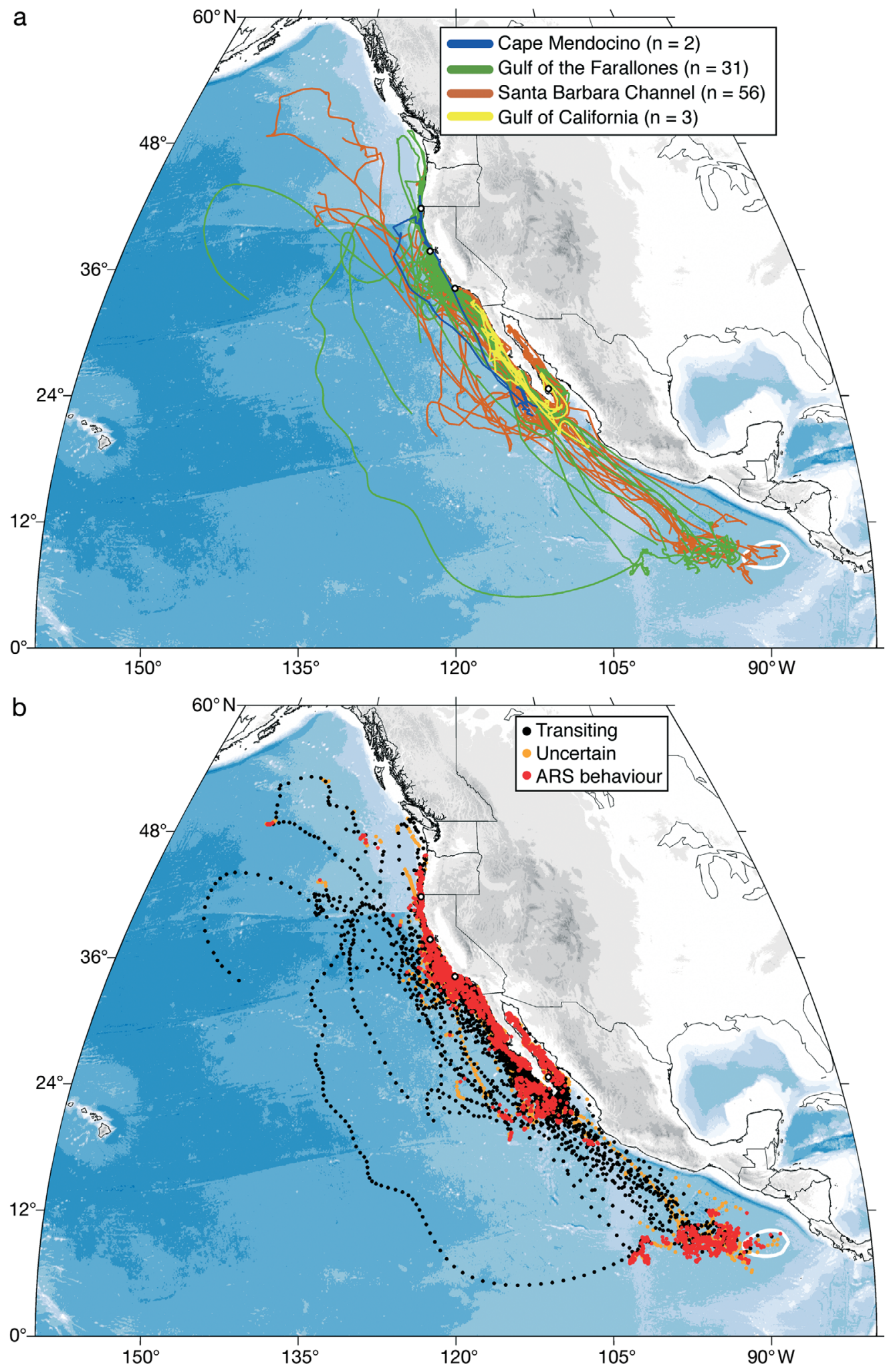

Fig. 1. Balaenoptera musculus. (a) Individual switching state-space model (SSSM)-derived tracks for 92 tags on blue whales deployed between 1994 and 2007 that transmitted for more than 7 d, colour coded by deployment location, and (b) all SSSM-derived locations from the 92 tags, colour coded by behavioural mode. In each panel, the 4 tag deployment locations are shown as white circles (o), the annual climatological position of the Costa Rica Dome (CRD) as a white contour and the bathymetry as shades of blue. ARS: area-restricted search. Map projection: sinusoidal (equal-area) 
where $\sigma_{\text {lon }}^{2}$ and $\sigma_{\text {lat }}^{2}$ are the process variances in longitude and latitude, respectively, and $\rho$ is the correlation coefficient. $b=1$ or 2 denotes behavioural mode 1 or mode 2 , and $\alpha$ represents the probabilities (Pr)

$$
\begin{aligned}
& \alpha_{1}=\operatorname{Pr}\left(b_{\mathrm{t}}=1 \mid b_{\mathrm{t}-1}=1\right) \\
& \alpha_{2}=\operatorname{Pr}\left(b_{\mathrm{t}}=1 \mid b_{\mathrm{t}-1}=2\right)
\end{aligned}
$$

These 2 behavioural modes are thought to represent transiting (mode 1) and ARS behaviour (mode 2), and priors were used assuming that during transiting, turn angles should be closer to 0 and autocorrelation should be higher than when foraging (Jonsen et al. 2007). The model was fit using a Bayesian approach in WinBUGS software (Lunn et al. 2000). Two chains were run in parallel, each for a total of 20000 Markov Chain Monte Carlo (MCMC) samples, the first 15000 were discarded as a burn-in and the remaining samples were thinned, retaining every tenth sample to reduce autocorrelation. Thus, posterior distributions for each parameter were based on 500 samples from each chain giving a total of 1000 independent samples (as in Bailey et al. 2008 and Eckert et al. 2008).

Analyses of movement behaviour. The movement behaviour of the whales was inferred from the SSSM. Although only 2 behavioural modes were modelled, the means of the MCMC samples provide a continuous value from 1 to 2 . A mean behavioural mode of $<1.25$ was considered transiting, whereas a value $>1.75$ represented ARS behaviour (Jonsen et al. 2007). Many of the whales were tagged while they were feeding (Mate et al. 1999), but no other behavioural observations were made along the tracks. The ARS behaviour may therefore be indicative of foraging, but could also be resting or breeding behaviour. Any locations with a mean behavioural mode between 1.25 and 1.75 were treated as uncertain (Jonsen et al. 2007).

Having determined the locations at which ARS behaviour occurred, a generalised linear mixed model (GLMM) was used to analyse the latitudinal positions of these locations $(y)$ to test for seasonal and interannual variation. The error distribution was Gaussian with an identity link function, and individual tracks were included as a random effect. Season $(S)$ was treated as a 4-level categorical variable (autumn [reference level since most tagging occurred during this period $]=$ September to November $;$ winter $=$ December to February; spring = March to May; summer $=$ June to August). Year $(Y)$ was also included as a categorical variable, with 2007 as the reference, as not all of the years were consecutive. Finally, tagging location $(T)$ was included as a categorical variable, with the Santa Barbara Channel as the reference level, to determine if whales from different areas behaved differently. The model was thus defined as:

$$
Y_{i j}=\alpha+\beta_{1} S_{i j}+\beta_{2} Y_{i j}+\beta_{3} T_{i j}+b_{i}+\varepsilon_{i j}
$$

with

$$
b_{i} \sim N\left(0, \sigma_{b}^{2}\right), \quad \varepsilon_{i j} \sim N\left(0, \sigma^{2}\right)
$$

where $\alpha$ represents the intercept, $\beta_{1}$ to $\beta_{3}$ are the coefficients for the fixed effects, $b_{i}$ is the random variable representing the deviation from the population mean of the mean latitude for the $i$ th whale track and $\varepsilon_{i j}$ is the deviation in latitude for observation $j$ on whale track $i$ from the mean latitude for whale $i$. The statistical analyses were carried out using $\mathrm{R}$ software version 2.4.1 (R Development Core Team 2006) and the contributed package nlme (Pinheiro et al. 2007).

Seasonal and interannual variation in the amount of time spent in ARS behaviour (proportion of tracking days per month) were also investigated using a GLMM with a binomial error distribution, logit link function and the individual tracks as a random effect in the $\mathrm{R}$ package lme4 (Bates \& Sarkar 2007). The explanatory variables were year, included as a categorical variable with 2007 as the reference, and season (month, m), included as a cyclical variable by converting it to 2 vectors that were defined by sine $\left(M_{S}\right)$ and cosine $\left(M_{C}\right)$ terms (Zar 1984):

$$
\begin{aligned}
& M_{S}=\sin (2 \pi \times m) / 12 \\
& M_{C}=\cos (2 \pi \times m) / 12
\end{aligned}
$$

The structure of the model was:

$$
\operatorname{logit} \operatorname{Pr}\left(P_{i j}\right)=\alpha+\beta_{1} M_{S i j}+\beta_{2} M_{C i j}+\beta_{3} Y_{i j}+b_{i}+\varepsilon_{i j}
$$

where $\operatorname{Pr}\left(P_{i j}\right)$ denotes the probability of being in ARS behaviour at observation $j$ on whale track $i$ and the logit link function is:

$$
\text { logit } \operatorname{Pr}\left(P_{i j}\right)=\ln \left(\frac{P_{i j}}{1-P_{i j}}\right)
$$

An ARS patch was defined as successive locations with a mean behavioural mode $>1.75$ (i.e. ARS behaviour), and ended when 3 or more consecutive locations had a lower mean behavioural mode (Bailey et al. 2008). The location, number and duration of these ARS patches were identified and compared between tracks. First-passage time (FPT) was used to assess the spatial scale of these patches (Fauchald \& Tveraa 2003). This is defined as the time taken to cross a circle of a given radius, which is centred around an animal's position. The positions need to be regularly spaced, and the track was therefore linearly interpolated every $10 \mathrm{~km}$ (the mean accuracy of SSSM locations based on low quality Argos positions; Bailey et al. 2008). The FPT was calculated for radii ranging from $10 \mathrm{~km}$ to 2 times the maximum daily step length (Bradshaw et al. 2007) at increments of $10 \mathrm{~km}$. The circle size at which there was a peak in the variance of the log-transformed FPTs 
identified the spatial scale at which search effort was concentrated for each of the individual tracks, and also for all tracks combined to identify a mean scale for all tagged animals (Fauchald \& Tveraa 2003). Differences in the spatial scale of search effort between years were compared using a 1-way analysis of variance (ANOVA). Since there was variation in the duration and maximum radius size for each of the tracks, the effect of this on the spatial scale identified was tested using linear regression.

As well as identifying ARS patches, we also quantified the animals' movements between them. Seasonal variation in the duration and distance between ARS patches was tested using a generalised linear model (GLM) with a Gaussian error distribution and identity link function, where season was treated as a 4-level categorical variable (autumn [reference level] = September to November; winter = December to February; spring $=$ March to May; summer = June to August). A GLMM was used to analyse the animals' speed over ground $\left(y_{S}\right)$ in relation to transiting or ARS behaviour $(B)$, with the individual tracks as a random effect. The error distribution was Gaussian with an identity link function.

$$
y_{S i j}=\alpha+\beta_{1} B_{i j}+b_{i}+\varepsilon_{i j}
$$

Analyses of SSSM performance. As the SSSM is fit using a Bayesian approach, the model is able to use prior information in its estimation (Jonsen et al. 2003). There was considerable development in tag design and attachment during the study period, resulting in differences in the track duration and number of satellite transmissions (Mate et al. 2007). Transmission duty cycling has also been employed on some occasions to conserve battery power and increase the operational life of the tags. Three categories of duty cycling were programmed into the tags: transmissions every day, transmissions every day for the first $90 \mathrm{~d}$ and then every $2 \mathrm{~d}$ following this, and tags that transmitted only every $2 \mathrm{~d}$. On transmission days, tags were scheduled to transmit every $7 \mathrm{~s}$ for four $1 \mathrm{~h}$ periods, with the $1 \mathrm{~h}$ periods scheduled to coincide with the times a satellite was most likely to be overhead. The effect of these factors on the precision of the SSSM estimates was investigated by calculating the width of the $95 \%$ credible limits for each daily SSSM location for a track that had 0 to 6 satellite locations $\mathrm{d}^{-1}$ (total duration $=194 \mathrm{~d}$ ) using linear regression. The effect of varying the amount of satellite data on behavioural mode estimation was also examined. A linear regression was applied to the proportion of uncertain behavioural mode locations in relation to track duration, mean number of satellite transmissions per day and duty cycling for all tracks.

\section{RESULTS}

\section{Blue whale tracks}

During 1993 to 2007, blue whale locations were successfully transmitted from 128 tags out of the 159 deployed. Deployment locations were: the Santa Barbara Channel $(\mathrm{n}=74)$, the Gulf of the Farallones ( $\mathrm{n}=$ 49), near Cape Mendocino ( $\mathrm{n}=2$ ), and the Gulf of California $(\mathrm{n}=3)$. The mean $( \pm \mathrm{SD})$ satellite track duration was $80 \pm 90 \mathrm{~d}$ (range $=0$ to $504 \mathrm{~d}$ ), and there was a significant increase in the tracking duration during the $14 \mathrm{yr}$ study period (linear regression: $F_{1,90}=8.012$, $\mathrm{p}<$ $0.01)$. Since there was a mean $( \pm \mathrm{SD})$ of $2 \pm 1.6$ satellite locations per day, the SSSM was run with an output of 1 location estimate per day. The SSSM was run on

Table 1. Balaenoptera musculus. Summary of tracking data for blue whales satellite tagged in 1993 to 2007 . SSSM: switching state-space model

\begin{tabular}{|c|c|c|c|c|c|c|c|}
\hline \multirow{2}{*}{$\begin{array}{l}\text { Deployment } \\
\text { year }\end{array}$} & \multirow{2}{*}{$\begin{array}{c}\text { No. of } \\
\text { tags }\end{array}$} & \multicolumn{3}{|c|}{$\ldots$ Duration $(\mathrm{d})$} & \multicolumn{2}{|c|}{ Mean no. of satellite locations } & \multirow{2}{*}{$\begin{array}{c}\text { No. of } \\
\text { SSSM tracks }\end{array}$} \\
\hline & & Mean & Min. & Max. & $\left(\operatorname{track}^{-1}\right)$ & $\left(d^{-1}\right)$ & \\
\hline 1993 & 4 & 4 & 0 & 7 & 5 & 0.9 & 0 \\
\hline 1994 & 9 & 4 & 1 & 14 & 18 & 4.5 & 2 \\
\hline 1995 & 14 & 18 & 1 & 81 & 38 & 2.4 & 8 \\
\hline 1998 & 9 & 75 & 1 & 241 & 113 & 2.3 & 7 \\
\hline 1999 & 19 & 98 & 2 & 262 & 113 & 1.2 & 15 \\
\hline 2000 & 12 & 70 & 1 & 284 & 70 & 1.8 & 6 \\
\hline 2001 & 1 & 214 & 214 & 214 & 280 & 1.3 & 1 \\
\hline 2002 & 2 & 146 & 97 & 194 & 273 & 1.7 & 2 \\
\hline 2004 & 19 & 90 & 1 & 504 & 162 & 2.4 & 16 \\
\hline 2005 & 15 & 87 & 3 & 235 & 120 & 1.5 & 14 \\
\hline 2006 & 9 & 143 & 1 & 326 & 102 & 1.0 & 7 \\
\hline 2007 & 15 & 114 & 1 & 222 & 143 & 1.6 & 14 \\
\hline Total & 128 & & & & & & 92 \\
\hline
\end{tabular}


tracks with a duration of more than $7 \mathrm{~d}$ to reduce bias caused by the tagging location and to provide sufficient information for behavioural estimation, resulting in 92 tracks (Table 1). The mean distance travelled based on these model-derived positions was $5430 \pm$ $4191 \mathrm{~km}$ (range $=290$ to $20860 \mathrm{~km}$ ).

\section{Movement behaviour}

Although tagging was concentrated off the coast of California, the blue whales moved as far north as the Gulf of Alaska and as far south as the eastern tropical Pacific (ETP) (Fig. 1a). The SSSM generally distinguished well between transiting ( $27 \%$ of locations) and ARS (43\%) behavioural modes, with $30 \%$ of locations remaining as uncertain (Fig. 2). ARS behaviour mainly occurred off the coasts of Oregon, California and Baja California, as well as within the Gulf of California and west of the Costa Rica Dome (CRD) in the ETP (Fig. 1b). Movements were generally north-south and close to the continental margin. The latitude of ARS behaviour was significantly farther south during winter, spring and summer than in autumn, indicating a southward migration to wintering grounds in the Gulf of California and west of the CRD, and return northward migration to Baja California, California and Oregon (Fig. 3, Table 2). There was also significant interannual variation, with ARS behaviour occurring farther north in 2000, 2004, 2005 and 2006 than in 2007. There was also a track in 2007 that displayed foraging behaviour in the Gulf of Alaska in winter (Fig. 3). We found no significant effect of the tagging location on the latitude of ARS behaviour (Table 2).

The mean $( \pm \mathrm{SD})$ percentage of track time that was spent in ARS behaviour was $29 \pm 31 \%$ (range = 0-99\%). The proportion of tracking days in ARS behaviour per month varied significantly seasonally and interannually (Table 2), being highest in January and June/July (Fig. 4a). There was significantly less time spent in ARS behaviour in 1995, 1999, 2004, 2005 and 2006 than in 2007, but more in 2008 (Fig. 4b).

There was a mean $( \pm \mathrm{SD})$ of $2 \pm 2.81$ ARS patches per track, with a maximum of 13 . The mean time spent within the largest ARS patch for each track was $21 \pm$

Fig. 2. Balaenoptera musculus. Distributions of movement parameters in transiting (black) and area-restricted search (ARS) modes (red) averaged for each blue whale track for (a) travel speed, calculated from consecutive mean switching state-space model (SSSM)-derived locations, (b) mean turning angle $(\theta)$ where $0^{\circ}$ is straight ahead, and (c) autocorrelation in speed and direction $(\gamma)$. These latter 2 parameters were based on the means from the Markov Chain Monte Carlo (MCMC) samples for each track

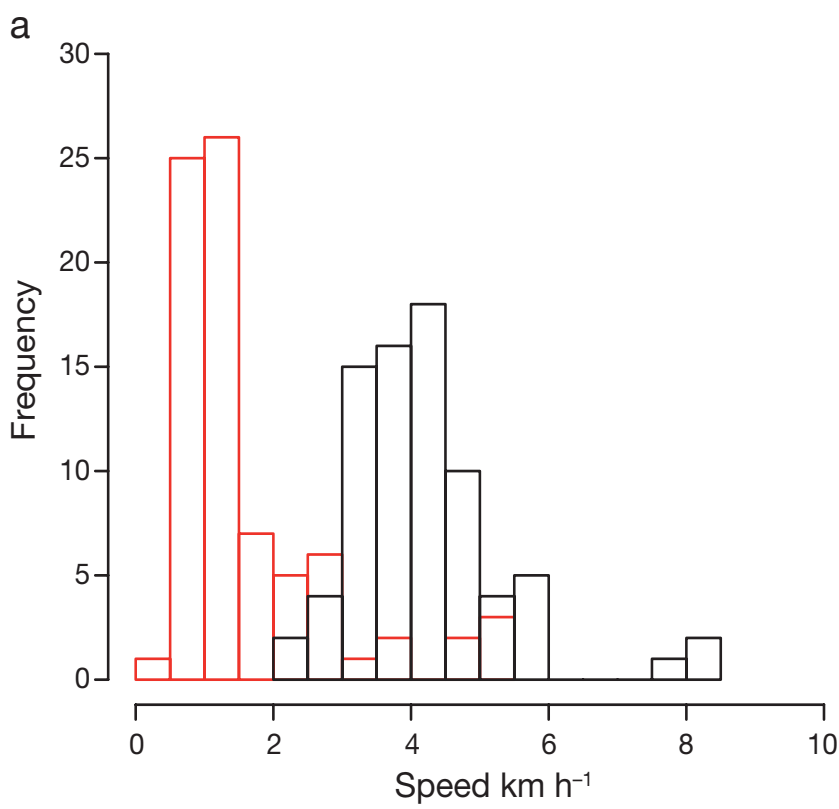

b Mean turning angle $(\theta)$

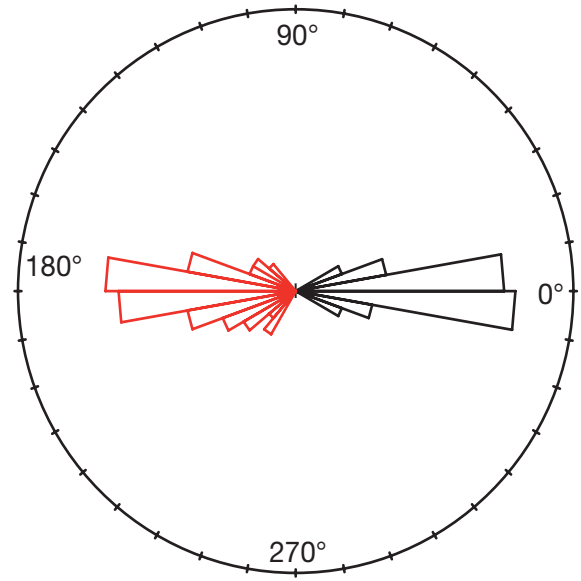

C

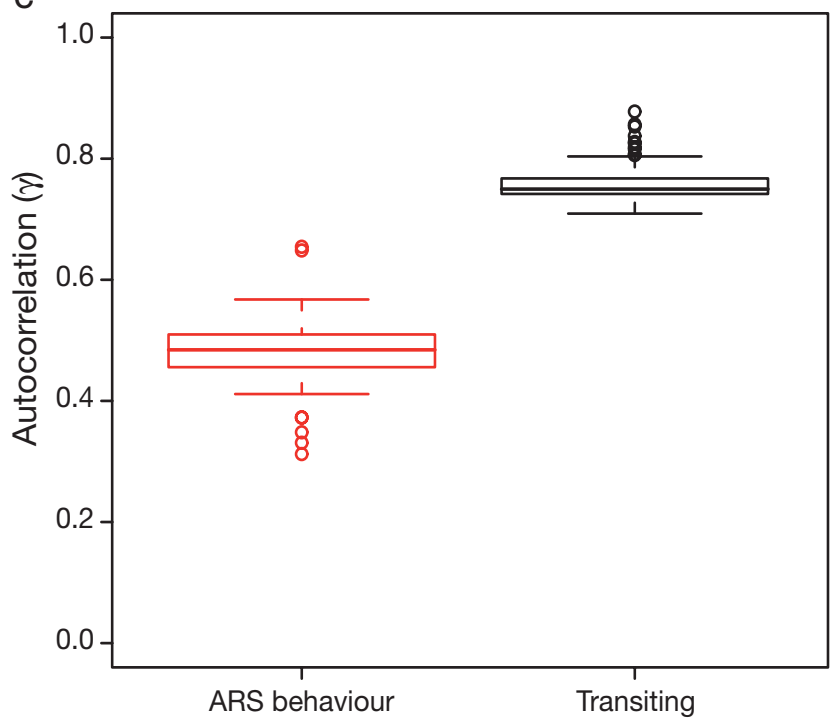




\section{a}
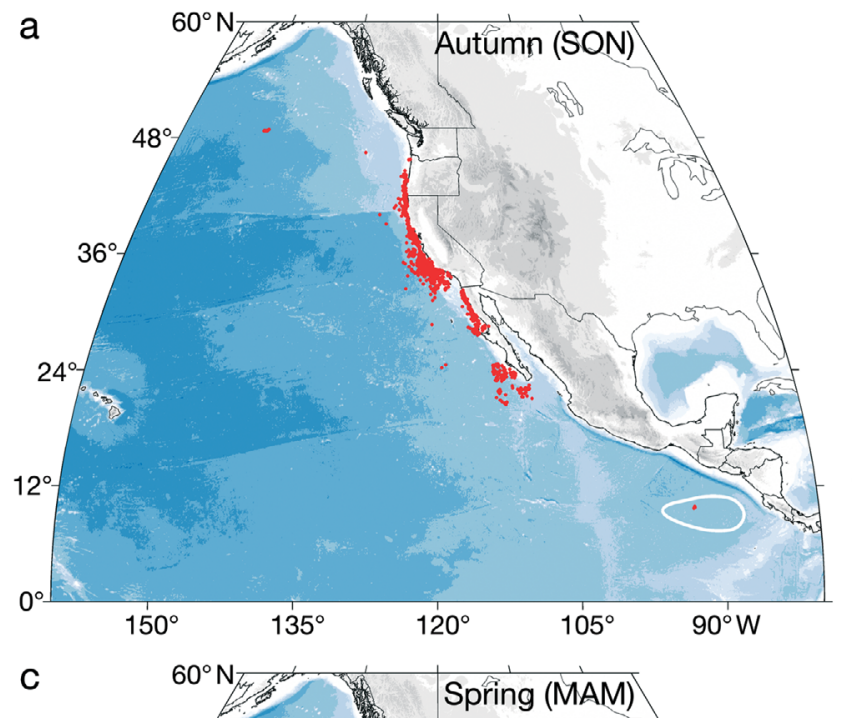
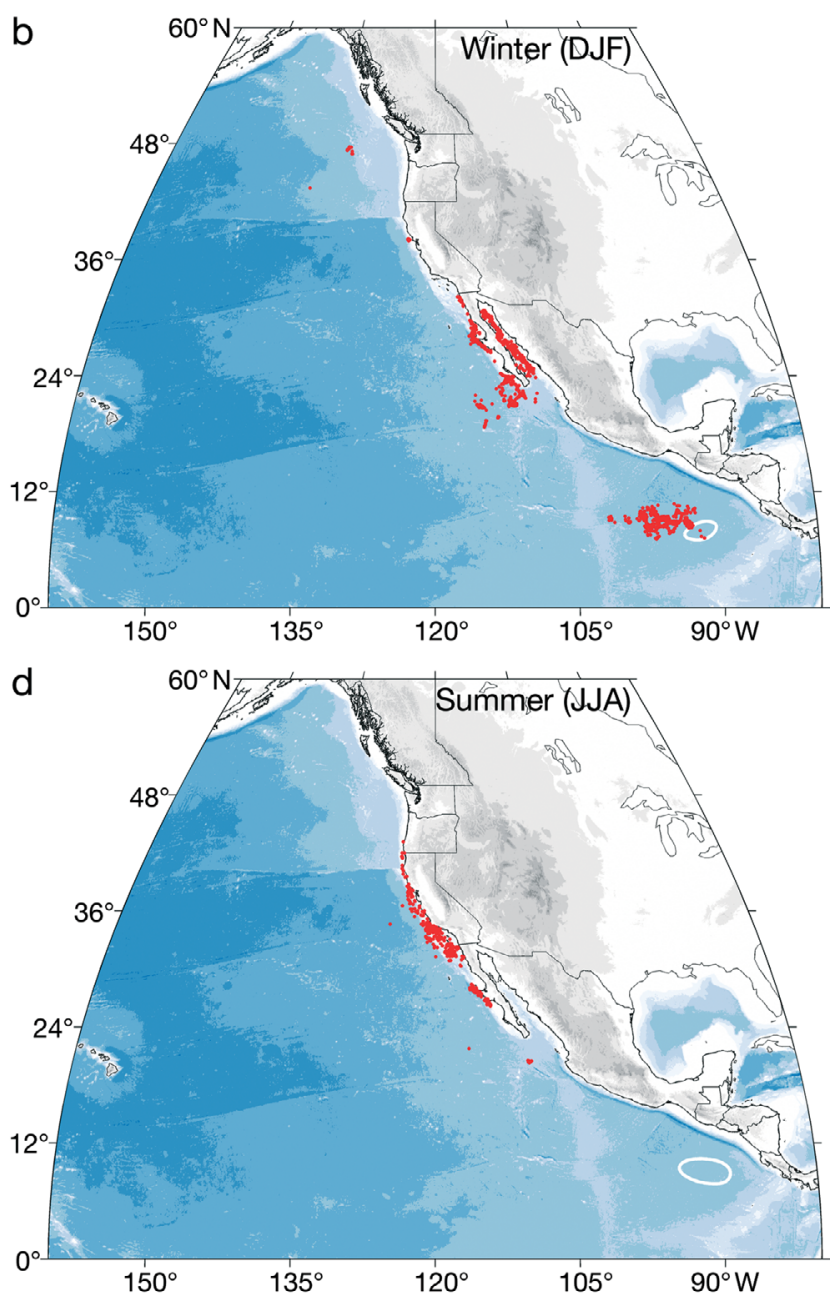

Fig. 3. Balaenoptera musculus. Switching state-space model (SSSM)-derived locations classified as area-restricted search (ARS) behaviour (red dots) in (a) autumn (September to November), (b) winter (December to February), (c) spring (March to May) and (d) summer (June to August). In each panel the climatological position of the Costa Rica Dome (CRD) for October, January, April and July, respectively, is shown as a white contour, and the bathymetry as shades of blue. Map projection: sinusoidal (equal-area)

$27 \mathrm{~d}$ (range $=3-115 \mathrm{~d}$ ). We observed a high degree of overlap in the location of these areas between animals. From north to south, they mainly occurred in the Gulf of the Farallones, in the Southern California Bight, along the northern coast of Baja California and off the tip of Baja California (Fig. 5). In the ETP, 4 large ARS patches occurred in 3 different years and were initiated at very similar latitude $\left(\sim 9^{\circ} \mathrm{N}\right)$ despite being almost $10^{\circ}$ apart in longitude. Therefore, although the mean latitude of ARS behaviour varied interannually, there were still consistent areas that were visited in several different years.

There was a significant positive relationship between the number of locations within a track and the peak spatial scale identified by FPT, but not with the maximum radius size (linear regression: $F_{1,79}=39.20$ and 1.73, p $<0.01$ and $p=0.19$, respectively). This rela- tionship was mainly caused by a few short tracks and therefore only those tracks with 50 or more locations were included in further analyses of FPT. The ARS patch spatial scale identified by FPT ranged from 10 to $360 \mathrm{~km}$ radius, but the mean variance for all tracks combined peaked at a scale of $50 \mathrm{~km}$ radius (Fig. 6a). There was high variability in the patch spatial scale between tracks and no significant difference between years (ANOVA: $F_{8,49}=1.37, \mathrm{p}=0.23$; Fig. $6 \mathrm{~b}$ ).

The whales' speed over ground (mean $\pm \mathrm{SD}=2.64 \pm$ $1.23 \mathrm{~km} \mathrm{~h}^{-1}$ ) was significantly faster during transiting $\left(3.70 \pm 2.15 \mathrm{~km} \mathrm{~h}^{-1}\right)$ than ARS behaviour (1.05 \pm $0.97 \mathrm{~km} \mathrm{~h}^{-1}$; Fig. 2, GLMM: $\left.|t|=21.73, \mathrm{p}<0.01\right)$. The distance (GLM: $F_{3,172}=5.18, \mathrm{p}<0.01$ ) and duration (GLM: $F_{3,172}=4.07, \mathrm{p}<0.01$ ) between ARS patches was significantly longer during winter (mean $=25 \mathrm{~d}$ and $2118 \mathrm{~km}$ ) than in autumn (mean = $14 \mathrm{~d}$ and $888 \mathrm{~km})$. 
Table 2. Parameter estimates from generalized linear mixed models for latitude of area-restricted search (ARS) behaviour (Gaussian error, identity link function), where the season autumn, year 2007 and the tagging location in the Santa Barbara Channel were the reference levels, and proportion of tracking days with ARS behaviour per month (binomial error, logit link function). $M_{S}$ and $M_{C}$ : sine and cosine vectors, respectively, for month; ${ }^{*} p<0.05$; - factors that were not included in the model

\begin{tabular}{|c|c|c|c|c|c|c|c|}
\hline \multirow{3}{*}{\multicolumn{2}{|c|}{ Factor }} & \multicolumn{6}{|c|}{ - Response - } \\
\hline & & \multirow{2}{*}{$\overline{\text { Estimate }}$} & \multicolumn{2}{|c|}{ Latitude -} & \multicolumn{3}{|c|}{$\longrightarrow$ Proportion } \\
\hline & & & $\mathrm{SE}$ & $\mathrm{p}$ & Estimate & $\mathrm{SE}$ & $\mathrm{p}$ \\
\hline \multicolumn{2}{|c|}{ Intercept } & 29.37 & 0.97 & $<0.01^{*}$ & -0.67 & 0.33 & $0.04^{*}$ \\
\hline \multicolumn{2}{|c|}{ Season: winter } & -9.15 & 0.20 & $<0.01^{*}$ & - & - & - \\
\hline & spring & -6.69 & 0.28 & $<0.01^{*}$ & - & - & - \\
\hline & summer & -1.04 & 0.21 & $<0.01^{*}$ & - & - & - \\
\hline \multicolumn{2}{|c|}{ Month: $M_{S}$} & - & - & - & -0.77 & 0.07 & $<0.01^{*}$ \\
\hline & $M_{C}$ & - & - & - & 0.20 & 0.05 & $<0.01^{*}$ \\
\hline \multirow[t]{11}{*}{ Year: } & 1994 & - & - & - & -14.47 & 269.92 & 0.96 \\
\hline & 1995 & 3.43 & 2.99 & 0.26 & -2.32 & 0.87 & $<0.01^{*}$ \\
\hline & 1998 & 2.87 & 2.92 & 0.33 & -1.39 & 0.88 & 0.11 \\
\hline & 1999 & 1.83 & 1.57 & 0.24 & -1.57 & 0.55 & $<0.01^{*}$ \\
\hline & 2000 & 3.99 & 1.57 & $0.01^{*}$ & 0.06 & 0.54 & 0.91 \\
\hline & 2001 & 2.24 & 1.67 & 0.18 & 0.58 & 0.57 & 0.31 \\
\hline & 2002 & 5.64 & 6.85 & 0.41 & 0.33 & 1.45 & 0.82 \\
\hline & 2004 & 11.07 & 0.84 & $<0.01^{*}$ & -1.32 & 0.34 & $<0.01^{*}$ \\
\hline & 2005 & 7.98 & 0.71 & $<0.01^{*}$ & -1.23 & 0.28 & $<0.01^{*}$ \\
\hline & 2006 & 2.55 & 0.44 & $<0.01^{*}$ & -0.79 & 0.18 & $<0.01^{*}$ \\
\hline & 2008 & - & - & - & 0.41 & 0.15 & $<0.01^{*}$ \\
\hline \multicolumn{8}{|c|}{ Tagging location: } \\
\hline \multicolumn{2}{|c|}{ Cape Mendocino } & 3.29 & 6.15 & 0.59 & - & - & - \\
\hline \multicolumn{2}{|c|}{ Gulf of the Farallones } & -2.38 & 1.41 & 0.10 & - & - & - \\
\hline \multicolumn{2}{|c|}{ Gulf of California } & -3.42 & 5.58 & 0.54 & - & - & - \\
\hline
\end{tabular}

than $50 \%$ of locations will be classified as uncertain behavioural mode. There was no significant effect of the duty cycle on reducing the certainty of the behavioural mode classification (linear regression: $F_{2,87}=$ 0.71, $\mathrm{p}=0.49$ ).

\section{DISCUSSION}

There are few, if any, whale populations for which the year-round movements are well known. The Northeast Pacific population of blue whales has been studied using acoustic, line-transect and photoidentification techniques in different parts of their range (e.g. Stafford et al. 1999, Calambokidis \& Barlow 2004), but little was known of their fine-scale movements, migratory routes and speeds. The progression of tag design and attachment methods spanning 14 yr has now enabled the duration of tracks to exceed 8 mo on many occasions, with one lasting $504 \mathrm{~d}$. We have consequently identified migratory routes down to wintering locations in the ETP and the Gulf of Califor-

\section{SSSM performance}

There was a significant negative relationship between the width of the SSSM location 95\% credible limits and the number of satellite locations per day and the number of SSSM locations previously in the track, but not with the number of satellite locations in the previous day (linear regression: $F_{1,189}=21.21,8.14$ and $0.49 ; \mathrm{p}<0.01, \mathrm{p}<0.01$ and $\mathrm{p}=0.49$, respectively). The credible limits were therefore narrower, indicating higher precision in the location estimation, when there were more satellite data within each time interval a SSSM location was being estimated, and a larger number of earlier SSSM locations from which to gain information.

There was also a significant negative relationship between the proportion of daily locations that were classified as uncertain behavioural mode $(u)$, and the track duration ( $(l)$ and mean number of satellite transmissions per day for the track ( $s$ ) (linear regression: $u$ $=0.72-0.0021-0.06 s_{;} F_{1,87}=32.19$ and 5.07; $\mathrm{p}<0.01$ and $\mathrm{p}<0.05$, respectively). Based on this, about 80 locations and a mean of at least 3 satellite locations per day (or time interval) are required to ensure less nia, as well as monitored the movements of numerous whales while on their summer foraging grounds.

The individual whale movements presented in this study showed that the animals travelled thousands of $\mathrm{km}$ annually and confirmed that the population of blue whales off California and Mexico ranges throughout the Northeast Pacific (Stafford et al. 1999, Gilpatrick \& Perryman 2008). Whales ranged up to Vancouver Island in 3 years $(2004,2005,2007)$ with 1 whale spending the months of October and November 2007 in the Gulf of Alaska before migrating south. Some authors have interpreted the recent presence of blue whales in these areas as evidence that the whales are returning to regions where they were historically harvested (Rice 1974, Gregr \& Trites 2001, Calambokidis et al. 2009), perhaps in response to shifts in prey availability driven by changes in oceanographic conditions (Calambokidis et al. 2009).

Migratory routes were primarily close to the continental margin, with occasional movements offshore and a relatively straight, directed winter movement in December to February to 3 areas: (1) the southern tip of Baja California, (2) the Gulf of California, and (3) west of the CRD near $9^{\circ} \mathrm{N}$ (Fig. 3). Whales wintering 
in the Gulf of California ranged throughout the Gulf, particularly in the deep central basins and along its western side. While the whales generally followed a direct route during the southward migration, they often made extended stops off the central and northern Baja California coast during the northward migration, typically leaving their wintering grounds in March and April, but not arriving in Californian waters until June. Of the 3 whales tagged in the Gulf of California (1 in 2001, 2 in 2002), none were tracked to the typical summer feeding grounds off California. One whale was only tracked until 28 June 2002, so it is possible it reached Californian waters after the tag stopped transmitting. However, the other 2 whales
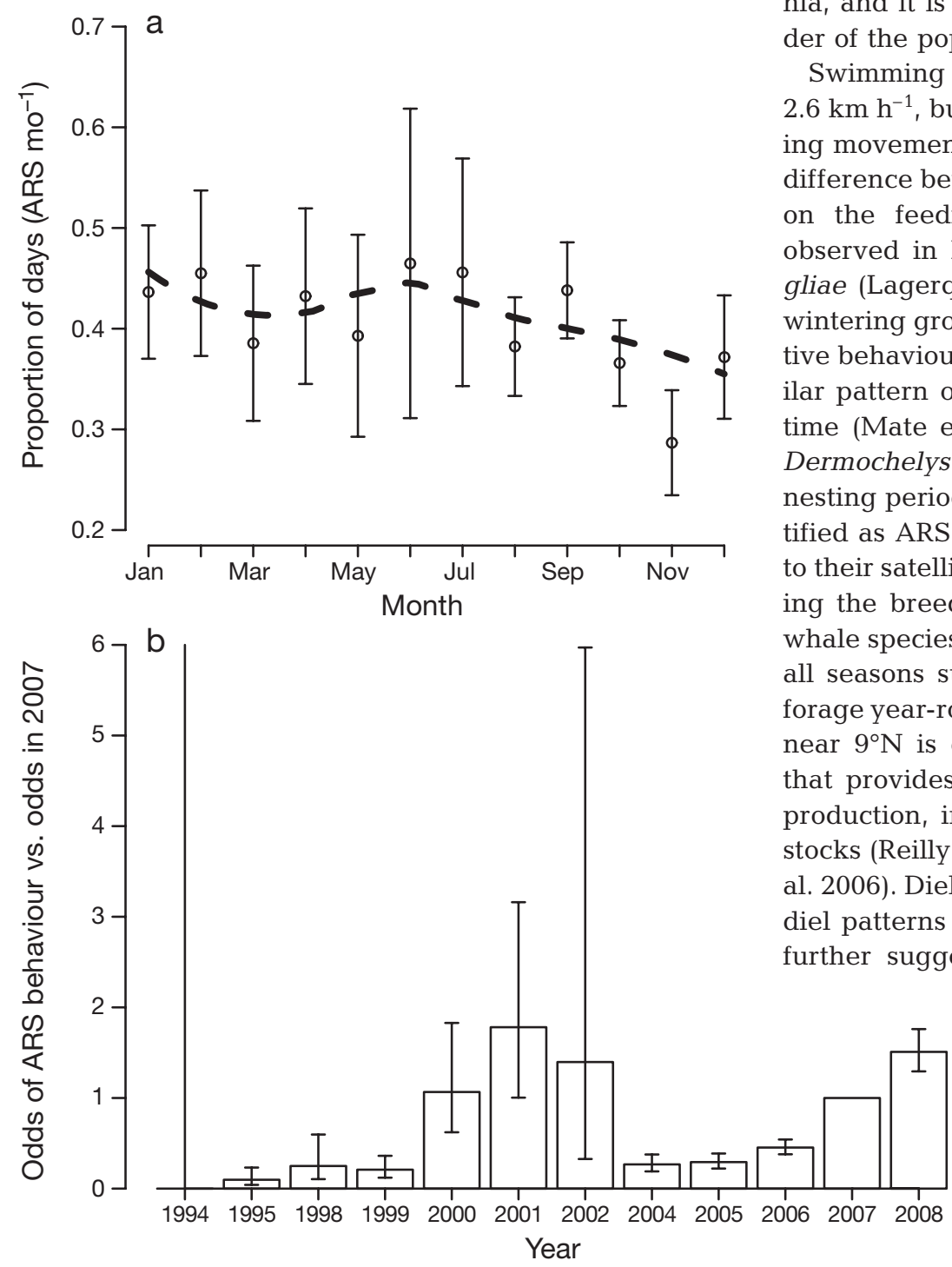

Fig. 4. Balaenoptera musculus. Mean $( \pm \mathrm{SE})$ proportion of tracking days $\mathrm{mo}^{-1}$ for blue whales in area-restricted search (ARS) behavioural mode (0) in relation to (a) month, and best-fit line for the generalized linear mixed model (GLMM)-fitted values, and (b) year, given as odds ratios ( \pm SE) from the GLMM where 2007 is the reference level. Note years are not all consecutive were tracked until 26 October 2001 and 1 October 2002, which would be very late for them to arrive at the feeding grounds in California. This raises the possibility that not all Northeast Pacific blue whales summer in California, which would affect current population estimates based on animals found within US waters. A marked decrease in blue whale abundance estimates from 1991-1996 to 2001-2005 along the US west coast may therefore have been caused by a change in distribution rather than a population decline (Benson et al. 2002, Barlow \& Forney 2007). It should also be noted that our inference is based on sampling animals that occurred at the 4 tagging sites, mainly tagged during autumn off the coast of California, and it is possible that habitat use by the remainder of the population could differ.

Swimming speeds over ground were on average $2.6 \mathrm{~km} \mathrm{~h}^{-1}$, but were significantly faster during transiting movements than during ARS behaviour. A similar difference between swim speeds during migration and on the feeding and wintering grounds has been observed in humpback whales Megaptera novaeangliae (Lagerquist et al. 2008). ARS behaviour on the wintering grounds may be representative of reproductive behaviour since other whale species exhibit a similar pattern of short localized movements during this time (Mate et al. 1998). Similarly, leatherback turtle Dermochelys coriacea movements during the internesting period near the nesting beach were also identified as ARS behaviour when this SSSM was applied to their satellite tracks (Bailey et al. 2008). Fasting during the breeding season is common in many baleen whale species, but the occurrence of ARS behaviour in all seasons suggests the possibility that blue whales forage year-round. The wintering area west of the CRD e conditions for enhanced biological including enhanced euphausild standing (2002, Ballance et die ns in the vertical distribution of their prey, g that feeding occurs in this area (Stafford et al. 2005). The Gulf of California also has dense concentrations of euphausiids during the winter and spring (Tershy 1992), when tagged blue whales were present and ARS behaviour occurred. Red crabs Pleuroncodes planipes appear in great abundance along parts of the Pacific coast of Baja California (Longhurst 2004) and may explain the extended stops and concentration of blue whale ARS patches there during the spring migration north (Fig. 5). 


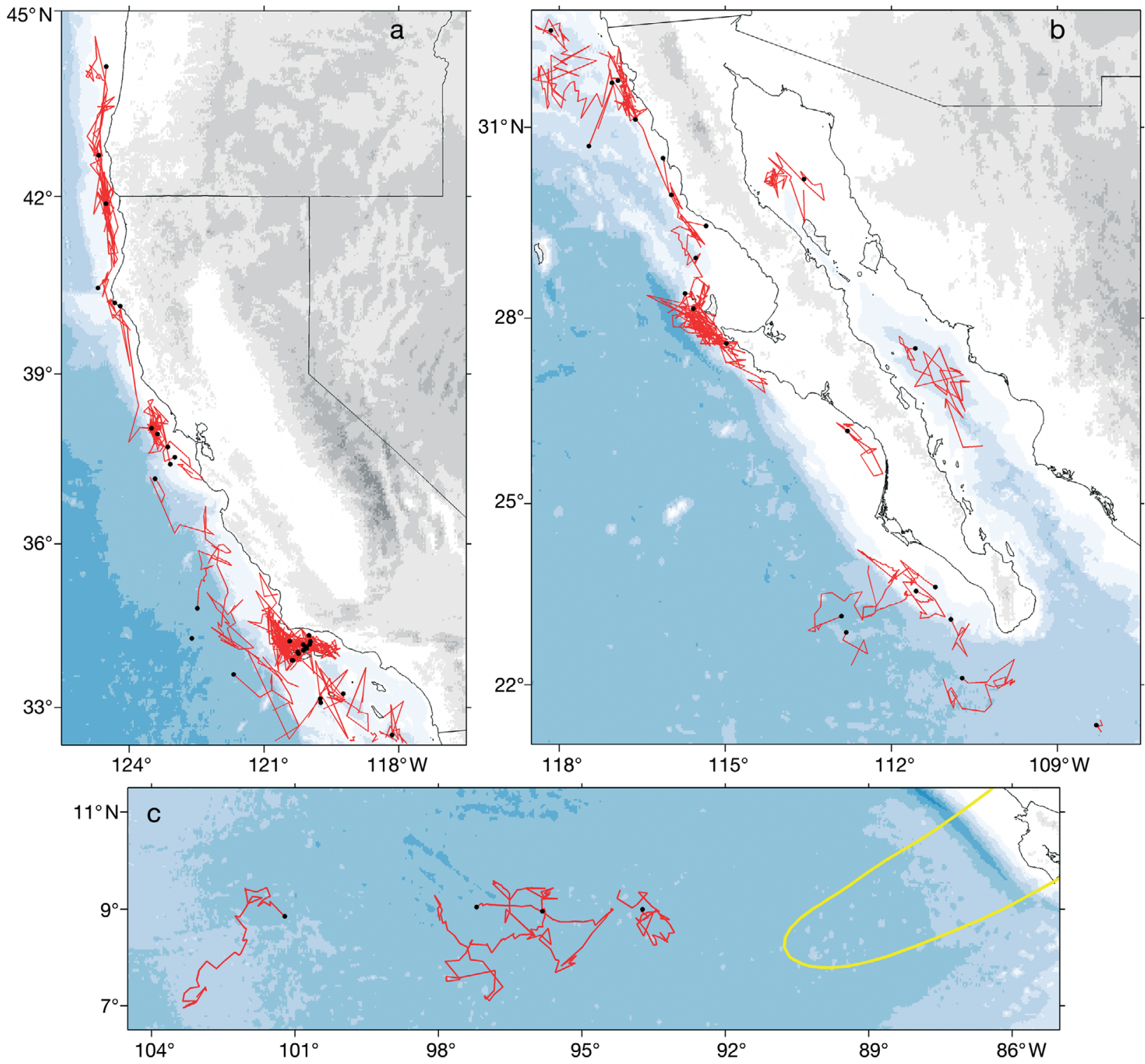

Fig. 5. Balaenoptera musculus. Largest switching state-space model (SSSM)-derived area-restricted search (ARS) patch for each track (red lines, with black circles showing the start location of each patch) for 3 regions: (a) United States, (b) Mexico, and (c) eastern tropical Pacific (the February climatological position of the Costa Rica Dome [CRD] is shown as a yellow contour). Map projection: Mercator (conformal)

The long durations of ARS behaviour (21 d on average) suggest that once blue whales have reached a suitable site, they remain there for a prolonged period of time. In this study, we were clearly limited by the resolution of the satellite tracking data and the daily time step, and therefore we do not attempt to identify individual feeding events (Calambokidis et al. 2007). However, these larger-scale ARS patches may represent areas where multiple feeding events have occurred, indicating dense aggregations of prey. The spatial scale of the ARS patches did not significantly differ between years and may indicate that blue whales require a threshold density of prey for these multiple feeding events to be energetically profitable (Acevedo-Gutiérrez et al. 2002). The high degree of overlap observed in ARS patches at known biological hot spots (Gulf of the Farallones: Palacios et al. 2006; Channel Islands: Fiedler et al. 1998; northern Baja California and the southern tip of Baja California: Etnoyer et al. 2004, 2006) suggests that there may be relatively few areas in the Northeast Pacific that meet this threshold.

Euphausiids form a key trophic link in coastal upwelling systems between primary production and 

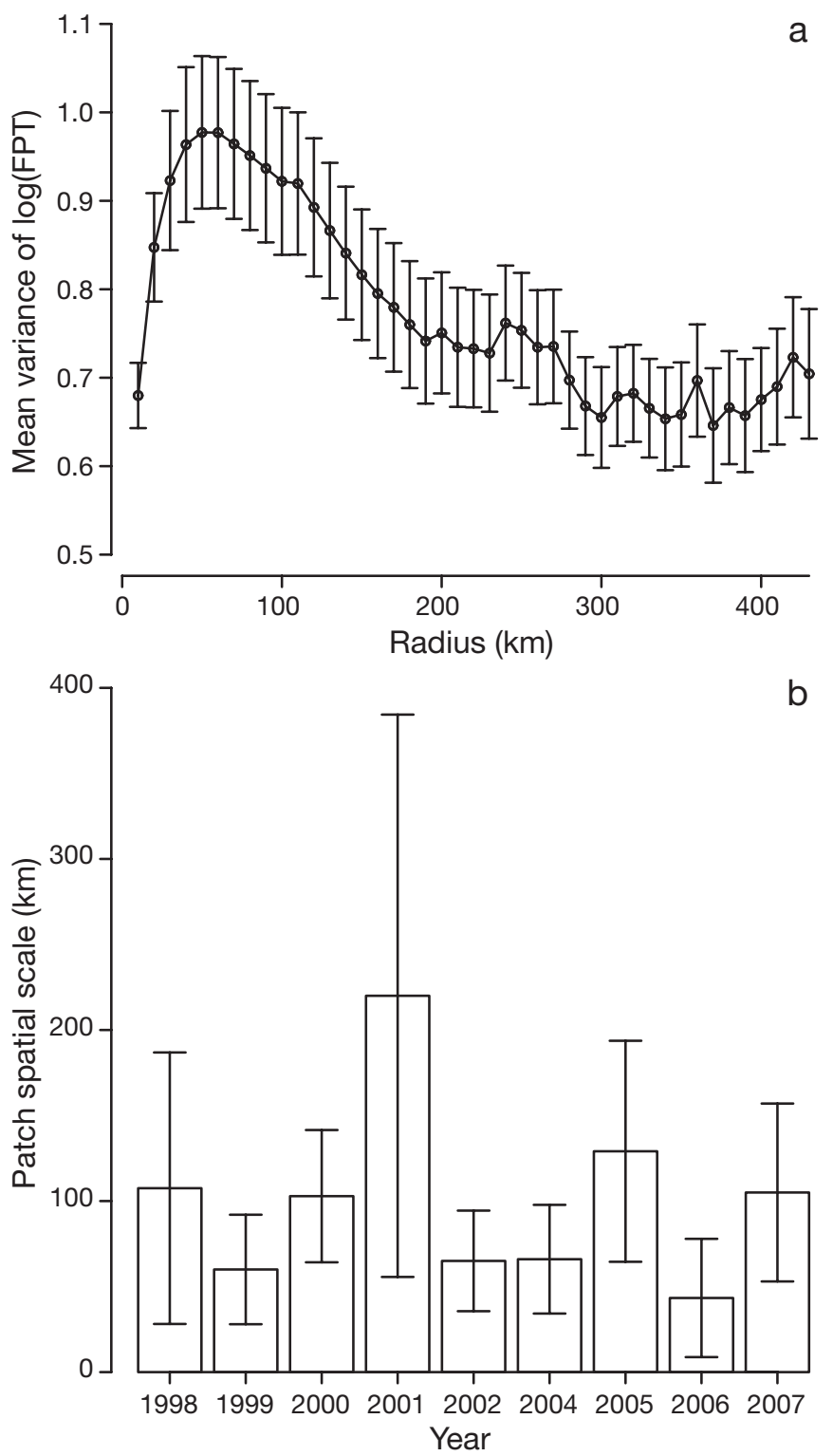

Fig. 6. Balaenoptera musculus. (a) Mean variance $( \pm \mathrm{SE})$ in log-transformed first-passage time (FPT) vs. circle radius for tracks of blue whales with at least 50 daily locations $(n=58)$. The peak in variance occurred at a search radius of $50 \mathrm{~km}$. (b) Mean $( \pm 95 \%$ CI) FPT patch spatial scale (circle radius) in relation to year. Note years are not all consecutive

higher-trophic-level consumers. The California Current System is a highly productive ecosystem driven by seasonal wind-driven upwelling (Croll et al. 2005). However, the timing, duration and intensity of this upwelling varies significantly interannually (Bograd et al. 2009) and consequently affects euphausiid abundance (Mangel et al. 2002). This may be driving the variation in the location and duration of ARS as the whales modify their foraging behaviour in response to their prey. For example, a dramatic reduction in zoo- plankton biomass offshore during the 1997-98 El Niño event led to the concentration of baleen whales in the productive coastal waters of Monterey Bay (Benson et al. 2002). Other evidence indicated an increased number of blue whales farther north, off Washington and Vancouver Island, during this event (Burtenshaw et al. 2004). Similarly, delayed upwelling and anomalously warm sea surface temperatures during 2005 (Pierce et al. 2006, Schwing et al. 2006) led to redistributions in phytoplankton and prey abundance (Brodeur et al. 2006, Thomas \& Brickley 2006), causing male California sea lions Zalophus californianus to forage longer and farther offshore (Weise et al. 2006). Our study has shown that blue whales responded to the lack of prey in this year by moving farther north.

The peak of ARS behaviour occurred in January and June/July, at the end of both the southward and northward migrations. The January peak in ARS behaviour is likely a result of the whales having reached their wintering grounds, whether that means feeding, breeding, or simply resting after a long journey. The second peak in ARS behaviour locations during June and July is more likely related to foraging, as zooplankton biomass typically increases dramatically in July in the California Current (Hayward \& Venrick 1998, Croll et al. 2005). In the Northern California Current, euphausiid patches were mainly observed along the continental shelf and upper slope, and were associated with areas of weak flow and retention (Ressler et al. 2005). This may explain why the blue whales generally remain close to the continental margin.

The SSSM distinguished between transiting and ARS behaviour for the majority of locations. In cases where the behavioural mode of a location was uncertain, this was generally caused by short track durations or a scarcity of satellite fixes. The classification of ARS behaviour would benefit from additional information from other sensors or visual observations to validate whether the animals are actually feeding, resting or breeding, although the long ARS durations suggest that it cannot all be resting. The number of behavioural modes in the model could be expanded to better describe the range of possible behaviours (Jonsen et al. 2005). The variable number of tracks and durations in each year meant that there was limited power to detect interannual differences and these may have been underestimated. Comparison of blue whale movements with environmental characteristics, such as sea surface temperature, upwelling indices, primary productivity and euphausiid abundance, would help to elucidate the factors influencing their movements and those responsible for differences in their ARS behaviour (Etnoyer et al. 2006, Irvine 2007). Previously, a state-space model (SSM) was used to first obtain 
improved animal position estimates and then associated environmental data were modelled in a second stage (Eckert et al. 2008). However, development of the SSM to incorporate covariates could provide a more direct estimate of environment-behaviour relationships (Schick et al. 2008).

The Northeast Pacific blue whales may be the largest remnant population in the world of this endangered species. Their large size and associated highenergy requirement means they must feed on dense concentrations of food, which may make them particularly vulnerable to perturbations in prey abundance (Acevedo-Gutiérrez et al. 2002, Benson et al. 2002, Croll et al. 2005). These whales travel hundreds of $\mathrm{km}$ between ARS patches, mainly along the Pacific coast of North America. The animals appear to respond to environmental variation by feeding farther north, rather than within smaller ARS patches. The large body size of blue whales makes searching and transiting between large dense prey patches possible because the cost of locomotion declines, while fasting ability increases with increasing body size (Brodie 1975). Strong similarities in the timing (November to January and March to June) and directionality to and from the ARS patch west of the CRD suggest that this may represent an important migration corridor (Fig. 1). While likely to be a breeding site (Pitman et al. 2007), like the Gulf of California, the abundance of prey in these areas during the winter and spring indicates that availability of food may also be important in determining the whales' migration destination. There were only occasional movements farther offshore, but no ARS behaviour was identified other than for 1 animal in the Gulf of Alaska, making the purpose of these offshore movements unclear. The long track durations obtained from electronic tagging have provided essential information about the critical habitats of Northeast Pacific blue whales and their variability.

Acknowledgements. This research was performed while H.B. held a National Research Council Research Associateship Award at NOAA/NMFS/SWFSC/Environmental Research Division. The National Marine Fisheries Service authorized this research under permit numbers 841 (1993-1998), 3691440 (1999-2004), and 369-1757 (2005-2010). Tagging in Mexican waters was conducted under permits issued by the Secretaría de Medio Ambiente y Recursos Naturales, Mexico (permit number DOO 02.8319 and SGPA/DGVS 0576). All research was approved by the Oregon State University Animal Care and Use Committee. Support was provided by the Tagging of Pacific Pelagics (TOPP) program of the Census of Marine Life, the Office of Naval Research (Grants 9610608, 0010085 and 0310861), the National Science Foundation, the Alfred P. Sloan Foundation, the Moore Foundation, the Packard Foundation, the National Geographic Society, and private donors to the Oregon State University Endowed Marine Mammal Institute. We especially thank F. Stewart and S. Stewart, whose generous support funded the first blue whale satellite tags. We thank all Marine Mammal Institute staff and volunteers for assistance on the research vessel, in the field and in developing the tags, and especially T. Follett for careful and diligent data-managing efforts. The monthly mean positions of the CRD used in Figs. 1, 3 and 5 were kindly provided by P. Fiedler. We are also particularly grateful to I. Jonsen, S. Jorgensen and B. Block for providing the statespace model code and for their valuable advice, and to J. Barlow, P. Fiedler, K. Newman and 3 anonymous reviewers for their constructive comments on this manuscript.

\section{LITERATURE CITED}

Acevedo-Gutiérrez A, Croll DA, Tershy BR (2002) High feeding costs limit dive time in the largest whales. J Exp Biol 205:1747-1753

Anderson-Sprecher R, Ledolter J (1991) State-space analysis of wildlife telemetry data. J Am Stat Assoc 86:596-602

Bailey H, Shillinger G, Palacios D, Bograd S, Spotila J, Paladino $F$, Block B (2008) Identifying and comparing phases of movement by leatherback turtles using state-space models. J Exp Mar Biol Ecol 356:128-135

Ballance LT, Pitman RL, Fiedler PC (2006) Oceanographic influences on seabirds and cetaceans of the eastern tropical Pacific: a review. Prog Oceanogr 69:360-390

Barlow J, Forney KA (2007) Abundance and population density of cetaceans in the California Current ecosystem. Fish Bull US 105:509-526

Bates D, Sarkar D (2007) lme4: linear mixed-effects models using S4 classes. R package. 0.999375-28. http://lme4.rforge.r-project.org

Benson SR, Croll DA, Marinovic BB, Chavez FP, Harvey JT (2002) Changes in the cetacean assemblage of a coastal upwelling ecosystem during El Niño 1997-98 and La Niña 1999. Prog Oceanogr 54:279-291

Bograd SJ, Schroeder I, Sarkar N, Qiu X, Sydeman WJ, Schwing FB (2009) Phenology of coastal upwelling in the California Current. Geophys Res Lett 36, L01602, doi: 10.1029/2008GL035933

> Bradshaw CJA, Sims DW, Hays GC (2007) Measurement error causes scale-dependent threshold erosion of biological signals in animal movement data. Ecol Appl 17: 628-638

> Branch TA, Stafford KM, Palacios DM, Allison C, and others (2007) Past and present distribution, densities and movements of blue whales Balaenoptera musculus in the southern hemisphere and northern Indian Ocean. Mammal Rev 37:116-175

Brodeur RD, Ralston S, Emmett RL, Trudel M, Auth TD, Phillips AJ (2006) Anomalous pelagic nekton abundance, distribution, and apparent recruitment in the northern California Current in 2004 and 2005. Geophys Res Lett 33, L22S08, doi:10.1029/2006GL026614

- Brodie PF (1975) Cetacean energetics, an overview of intraspecific size variation. Ecology 56:152-161

Burtenshaw JC, Oleson EM, Hildebrand JA, McDonald MA, Andrew RK, Howe BM, Mercer JA (2004) Acoustic and satellite remote sensing of blue whale seasonality and habitat in the Northeast Pacific. Deep-Sea Res II 51: 967-986

Calambokidis J, Barlow J (2004) Abundance of blue and humpback whales in the eastern North Pacific estimated by capture-recapture and line-transect methods. Mar Mamm Sci 20:63-85

> Calambokidis J, Schorr GS, Steiger GH, Francis J and others (2007) Insights into the underwater diving, feeding, and 
calling behavior of blue whales from a suction-cupattached video-imaging tag (Crittercam). Mar Technol Soc J 41:19-29

Calambokidis J, Barlow J, Ford JKB, Chandler TE, Douglas $A B$ (2009) Insights into the population structure of blue whales in the Eastern North Pacific from recent sightings and photographic identification. Mar Mamm Sci 25: 816-832

Charnov EL (1976) Optimal foraging, the marginal value theorem. Theor Popul Biol 9:129-136

> Corkeron PJ, Connor RC (1999) Why do baleen whales migrate? Mar Mamm Sci 15:1228-1245

Croll DA, Marinovic B, Benson S, Chavez FP, Black N, Ternullo R, Tershy BR (2005) From wind to whales: trophic links in a coastal upwelling system. Mar Ecol Prog Ser 289: $117-130$

Eckert SA, Moore JE, Dunn DC, van Buiten R, Eckert KL, Halpin PN (2008) Modeling loggerhead turtle movement in the Mediterranean: importance of body size and oceanography. Ecol Appl 18:290-308

Etnoyer P, Canny D, Mate B, Morgan L (2004) Persistent pelagic habitats in the Baja California to Bering Sea (B2B) ecoregion. Oceanography (Wash DC) 17:90-101

Etnoyer P, Canny D, Mate BR, Morgan LE, Ortega-Ortiz JG, Nichols WJ (2006) Sea-surface temperature gradients across blue whale and sea turtle foraging trajectories off the Baja California Peninsula, Mexico. Deep-Sea Res II 53: $340-358$

Fauchald P, Tveraa T (2003) Using first-passage time in the analysis of area-restricted search and habitat selection. Ecology 84:282-288

> Fiedler PC (2002) The annual cycle and biological effects of the Costa Rica Dome. Deep-Sea Res I 49:321-338

Fiedler PC, Reilly SB, Hewitt RP, Demer D and others (1998) Blue whale habitat and prey in the California Channel Islands. Deep-Sea Res II 45:1781-1801

Gilpatrick JW, Perryman WL (2008) Geographic variation in external morphology of North Pacific and Southern Hemisphere blue whales (Balaenoptera musculus). J Cetacean Res Manag 10:9-21

> Gregr EJ, Trites AW (2001) Predictions of critical habitat for five whale species in the waters of coastal British Columbia. Can J Fish Aquat Sci 58:1265-1285

Hayward TL, Venrick EL (1998) Nearsurface pattern in the California Current: coupling between physical and biological structure. Deep-Sea Res II 45:1617-1638

Heide-Jørgensen MP, Kleivane L, Øien N, Laidre KL, Jensen MV (2001) A new technique for deploying satellite transmitters on baleen whales: tracking a blue whale (Balaenoptera musculus) in the North Atlantic. Mar Mamm Sci 17:949-954

Irvine L (2007) Characterizing the habitat and diving behavior of satellite-tagged blue whales (Balaenoptera musculus) off California. MS thesis, Oregon State University, Newport, OR

> Jonsen ID, Myers RA, Fleming JM (2003) Meta-analysis of animal movement using state-space models. Ecology 84: 3055-3063

> Jonsen ID, Fleming JM, Myers RA (2005) Robust statespace modeling of animal movement data. Ecology 86: 2874-2880

> Jonsen ID, Myers RA, James MC (2007) Identifying leatherback turtle foraging behaviour from satellite-telemetry using a switching state-space model. Mar Ecol Prog Ser 337:255-264

Kareiva P, Odell G (1987) Swarms of predators exhibit 'preytaxis' if individual predators use area-restricted search. Am Nat 130:233-270
Lagerquist B, Mate B, Ortega Ortiz JG, Winsor M, UrbánRamirez J (2008) Migratory movements and surfacing rates of humpback whales (Megaptera novaeangliae) satellite tagged at Socorro Island, Mexico. Mar Mamm Sci 24:815-830

Longhurst A (2004) The answer must be red crabs, of course. Oceanography (Wash DC) 17:6-7

Lunn DJ, Thomas A, Best N, Spiegelhalter D (2000) WinBUGS - a Bayesian modelling framework: concepts, structure, and extensibility. Stat Comput 10:325-337

Mangel M, Marinovic B, Pomeroy C, Croll D (2002) Requiem for Ricker: unpacking MSY. Bull Mar Sci 70:763-781

Mate B, Gisiner R, Mobley J (1998) Local and migratory movements of Hawaiian humpback whales tracked by satellite telemetry. Can J Zool 76:863-868

> Mate B, Lagerquist B, Calambokidis J (1999) Movements of North Pacific blue whales during the feeding season off southern California and their southern fall migration. Mar Mamm Sci 15:1246-1257

> Mate B, Mesecar R, Lagerquist B (2007) The evolution of satellite-monitored radio tags for large whales: one laboratory's experience. Deep-Sea Res II 54:224-247

> Palacios DM, Bograd SJ, Foley DG, Schwing FB (2006) Oceanographic characteristics of biological hot spots in the North Pacific: a remote sensing perspective. Deep-Sea Res II 53:250-269

> Patterson TA, Thomas L, Wilcox C, Ovaskainen O, Matthiopoulos J (2008) State-space models of individual animal movement. Trends Ecol Evol 23:87-94

> Pierce SD, Barth JA, Thomas RE, Fleischer GW (2006) Anomalously warm July 2005 in the northern California Current: historical context and the significance of cumulative wind stress. Geophys Res Lett 33, L22S04, doi:10. 1029/2006GL027149

Pinheiro J, Bates D, DebRoy S, Sarkar D (2007) nlme: linear and nonlinear mixed effects models. R package. 3.1-90 www.r-project.org

Pitman RL, Fearnbach H, LeDuc R, Gilpatrick JW, Ford JKB, Balance LT (2007) Killer whales preying on a blue whale calf on the Costa Rica Dome: genetics, morphometrics, vocalisations and composition of the group. J Cetacean Res Manag 9:151-157

R Development Core Team (2006) R: a language and environment for statistical computing. R Foundation for Statistical Computing, Vienna. www.r-project.org

> Rasmussen K, Palacios DM, Calambokidis J, Saborío MT and others (2007) Southern hemisphere humpback whales wintering off Central America: insights from water temperature into the longest mammalian migration. Biol Lett 3:302-305

Reilly SB, Thayer VG (1990) Blue whale (Balaenoptera musculus) distribution in the eastern tropical Pacific. Mar Mamm Sci 6:265-277

Ressler PH, Brodeur RD, Peterson WT, Pierce SD, Vance PM, Røstad A, Barth JA (2005) The spatial distribution of euphausiid aggregations in the Northern California Current during August 2000. Deep-Sea Res II 52:89-108

Rice DW (1974) Whales and whale research in the eastern North Pacific. In: Schevill WE (ed) The whale problem. Harvard University Press, Cambridge, MA, p 170-195

> Robinson PW, Tremblay Y, Crocker DE, Kappes MA and others (2007) A comparison of indirect measures of feeding behaviour based on ARGOS tracking data. Deep-Sea Res II 54:356-368

Schick RS, Loarie SR, Colchero F, Best BD and others (2008) Understanding movement data and movement processes: current and emerging directions. Ecol Lett 11:1338-1350 
Schwing FB, Bond NA, Bograd SJ, Mitchell T, Alexander MA, Mantua N (2006) Delayed coastal upwelling along the U.S. west coast in 2005: a historical perspective. Geophys Res Lett 33, L22S01, doi:10.1029/2006GL026911

Sears R, Perrin WF (2009) Blue whale (Balaenoptera musculus). In: Perrin WF, Würsig B, Thewissen JGM (eds) Encyclopedia of marine mammals. Academic Press, San Diego, CA, p 120-124

Stafford KM, Nieukirk SL, Fox CG (1999) An acoustic link between blue whales in the eastern tropical Pacific and the northeast Pacific. Mar Mamm Sci 15:1258-1268

Stafford KM, Moore SE, Fox CG (2005) Diel variation in blue whale calls recorded in the eastern tropical Pacific. Anim Behav 69:951-958

Tershy BR (1992) Body size, diet, habitat use, and social

Editorial responsibility: Jason Matthiopoulos,

St. Andrews, UK behavior of Balaenoptera whales in the Gulf of California. J Mammal 73:477-486

Thomas AC, Brickley P (2006) Satellite measurements of chlorophyll distribution during spring 2005 in the California Current. Geophys Res Lett 33, L22S05, doi:10.1029/ 2006GL026588

Weise MJ, Costa DP, Kudela RM (2006) Movement and diving behavior of male California sea lion (Zalophus californianus) during anomalous oceanographic conditions of 2005 compared to those of 2004. Geophys Res Lett 33, L22S10, doi:10.1029/2006GL027113

Zar JH (1984) Biostatistical analysis. Prentice-Hall, Upper Saddle River, NJ

Zollner PA, Lima SL (1999) Search strategies for landscapelevel interpatch movements. Ecology 80:1019-1030

Submitted: April 17, 2009; Accepted: September 28, 2009

Proofs received from author(s): November 20, 2009 